\title{
Contribution of Planned Urban Green Spaces for Promoting Human Health Case of Chandigarh, India
}

Prabh, BEDI, School of Planning and Architecture, India

MAHAVIR, School of Planning and Architecture, India

Neha Goel TRIPATHI, School of Planning and Architecture, India

\begin{abstract}
Goal 11 of the Sustainable Development Goals has the seventh target of its Sustainable Cities and Communities focused on providing access to safe and inclusive green and public spaces. Principles of sustainable development necessitate that a balance is struck between environment and development to ensure healthy urban living. It has long been established that the presence of natural areas and planned open green spaces in and around urban settlements contributes to a quality of life by providing important ecological, social and psychological benefits to humans. In India, rapid urbanisation is resulting in significant land being used for developmental activities resulting in decline in open spaces across cities. It needs to be noted, the case in Chandigarh, India is different from rest of the country, where open spaces are considered as inviolable land use. Being a rare exception amongst the cities established immediately after India's Independence, urban greens were visualized and planned as an integral component in the city's Master Plan. Le Corbusier conceived the master plan of Chandigarh as analogous to human body, where green spaces symbolized the lungs. The greens in Chandigarh were created as functional, organized and natural spaces for integration and convergence of mind and body, that is the city as well as of its population. The research delves into the aspect of inclusivity of its various green spaces based on the social survey of the city's residents. The intent is to determine the usability and accessibility of the greens by the residents for various recreational, cultural and ecosystem services. The measures of inclusivity of the green spaces are defined to address the key question being researched upon, that is if green spaces have contributed to Chandigarh being a healthy city. Built upon the social survey tools, the authors discern the typologies of green spaces as the measure for building a healthy city contextualized for Chandigarh.
\end{abstract}

\section{Keywords}

Urban green spaces, Chandigarh, SDG-11, Sustainable City, Mental Wellbeing, Quality of Life

\section{Introduction}

There is an increasing trend in growth of urban population world over, with the projections of urban population increasing to approximately 68 percent of the total population, by 2050 (UN, 2018). With increasing pressure on resources, particularly land, there is a pertinent need to build and create balanced urban areas that are healthy and provide sustainable environment. For the purpose of this paper, the terms urban green spaces and open greens have been used interchangeably.

By 2051, India would be the most populous country with 1.70 billion people and per capita land availability would be 0.19 hectare. People living in urban areas would be 820 million constituting 48 percent of the total population (UN, 2018). Natural and environmental resources are adversely impacted by the high population growth and resultant high density in the cities. Studies have proven that green spaces are 
known to improve the quality of life by providing natural settings for recreation, thereby ensuring quality of basic resources as land, air and water.

Access to urban parks and green spaces is increasingly acknowledged to contribute to community wellbeing, develop social capital and enhance quality of urban life (Chiesura, 2004). As human society is increasingly becoming urbanised and congested, park provision is of strategic importance to improve the quality of urban life (Wolch et al., 2014). Research also indicates that access to certain urban facilities such as public parks and green spaces, affects land and property values, social activities, and even people's attitude to quality of life (Wang et al., 2103; Anderson and West, 2006; Colwell, 1985; Coughlin et al., 1974; Hannon, 1994).

\section{Concept, standards and policies}

From time-to-time, attempts have been made to standardize the green spaces in the urban areas by various international and national level agencies. In land use planning, Urban Greens Spaces (UGS) are the open spaces reserved for parks and include plant life, water feature and other kinds of natural environment.

Various techniques are adopted for creating standards for UGS. Some criteria that are frequently adopted are as population-ratio, area percentage, catchment area, facility specification and local standards (Veal, 2013). Population-ratio being the most used technique. Through the population-ratio, the amount of urban green space per 1,000 population or per person is allocated by the national or the state planning agencies that should be ideally achieved and maintained, irrespective of the rate of densification in the urban area.

\subsection{International}

World Health Organisation (WHO) considers Urban Green Spaces as an important investment that local authorities can make on behalf of citizens and their well-being. WHO defines UGS as all urban land covered by vegetation of any kind including on private and public grounds irrespective of size and function and can also include small water bodies as ponds, lakes and streams (blue spaces) (WHO, 2016).

It is recommended by WHO that every city should provide a minimum 9 square meters of UGS for each person provided it is safe, accessible and functional. WHO also suggests that an ideal amount of UGS can be generously provided as much as 50 square meters per person (Morar et.al., 2014). In case of India, average UGS is 08 square meters per person.

Open and Green Spaces are interchangeably used by Environmental Protection Agency, USA, where it is any piece of land that is undeveloped and has no building or other built structure) and is accessible to public (EPA, 2017). These include land that is party or completely covered with grass, trees, shrubs or other vegetation. It includes parks, community gardens and cemeteries. It also includes school yards, playgrounds, public seating areas, public plazas and vacant plots. Open spaces provide recreational areas for residents and help enhance the beauty of environmental quality and neighborhood. UGS provided in the cities like Los Angles and Washington are 48.5 and 38 square meters per person (Maryanti et.al., 2016).

It has been noted that 40 per cent of the surface area of European Cities is made up of urban green infrastructure with 18.2 square meters of publicly accessible green spaces per inhabitant (European Commission, 2019). 44 percent of urban population of Europe lives within 300 meters of a public park (European Commission, 2019). In the most livable city of the world, Vienna, as per Mercer's 2016 Quality of Living Survey, each of 1.7 million population has been provided with 120 square meters of UGS.

United Nations Sustainable Development Goals too drive to make urban areas sustainable with a wholistic approach particularly through its Goal 11, which specifically aims to make cities and human settlements 
inclusive, safe, resilient and sustainable. One of the targets (11.7) of this Goal is to provide universal access to safe, inclusive and accessible, green and public spaces.

It is to be noted as is obvious above that substantial variations have been observed in the UGS not only in intercity comparison, but these variations exist within the various sections of the same city as well. These are dependent on the population densities, land pressures and the economic wellbeing of the place.

\subsection{National}

India being a signatory to the UN SDG Goals has through its various national and state level policies and projects has attempted to meet SDG 11 (United Nations, 2017). One of the main such initiative is the Smart City Mission where under the area based and pan city development approaches, the need for UGS has been emphasised upon.

Green spaces in Indian context, also called as open spaces are defined as sites in a settlement, designated or designed as parks, gardens, playfields, sports facilities, maidan and outdoor recreational area (Kulshrestha, 2006).

Provision and management of the green spaces in urban areas lies within the purview of the planning and municipal authorities. The urban greens are classified under recreational use in the master plans. The planning authorities through a detailed analysis of the existing land use patterns, projected population and broad land uses allocate the areas under urban greens as per the prescribed norms in the guiding documents. The first guideline document, Urban Development Plan Formulation and Implementation Guidelines (UDPFI) in 1996 stated a recreational area to be 12-14 percent in small towns ${ }^{1}, 18-20$ percent in medium ${ }^{2}$ and large ${ }^{3}$ towns and $20-25$ percent in metropolitan ${ }^{4}$ cities.

Urban Greening Guidelines, 2014 (Town and Country Planning Organisation, 2014) act as model for the States particularly State Town Planning Departments, Urban Development Authorities and Urban Local Bodies which are responsible for planning and management of urban area at the local level. The typology of urban greens as per the Guidelines are reserved forests (typically do not fall in urban areas), protected forests (found in peri-urban and in some cases within urban areas) and national parks which typically fall within the purview of the state forest departments. District parks, neighborhood parks, tot lots, playgrounds, green belt, green strip and tree cover are the designated types as per the hierarchy in the urban area depending on the size of the settlement.

The revision to the UDPFI Guidelines, 1996 in 2014 called as Urban and Regional Development Plan Formulation and Implementation (URDPFI) Guidelines (Government of India, 2014) defined the open spaces as recreational spaces, organized greens and other common spaces such as vacant lands/open spaces including flood plains, forest cover in plain areas. The Guidelines prescribe 10-12 square meters of open space per person as desirable, which is slightly above the minimum prescribed norms of WHO. These norms are over and above the protected zones, ecological conservative areas in the hilly regions. A hierarchy of green spaces as prescribed in the 1996 Guidelines have been affirmed consisting of parks, playfields, other open spaces (Refer Table 4.2). For the plain areas, the size of the green spaces for each of the service levels has been adopted from Master Plan of Delhi - 2021. The norms for the hilly areas to have been prescribed based on the National Building Code, 2005 (Bureau of Indian Standards, 2005).

Table 2.1 Hierarchy of Open Spaces

\footnotetext{
${ }^{1}$ small towns - population between 5,000 to 50,000

2 medium towns - population between 50,000 to $1,00,000$

${ }^{3}$ large towns - population between 5,00,000 to $10,00,000$

4 metropolitan - population between $10,00,000$ to $50,00,000$
} 


\begin{tabular}{|l|l|r|r|}
\hline Service Level & Hierarchy of Services & Population & Area (Ha) \\
\hline Housing Cluster & 3-4 local parks and playgrounds & 5,000 & 0.50 \\
\hline Neighborhood & 3-4 local parks and playgrounds & 15,000 & 1.00 \\
\hline Community & 2-3 Community level parks and open spaces & 100,000 & 5.00 \\
\hline District/Zone & 1 district level park, sports complex, maidan & 500,000 & 25.00 \\
\hline Sub-city center & 1 City level park, sports complex, botanical garden, maidan & $1,000,000$ & 100.00 \\
\hline
\end{tabular}

Source: URDPFI Guidelines, 2014

The Guidelines have recommendations on the quality of the urban greens as well by way of specifications based on the climatic conditions, soil type, species and distance between the plantations. Specifications are provided for maintenance of the green spaces as well. The Guideline encourages the perforated tiling of the walkways.

Other than the quantum of area that is the number and size of the UGS, its typology and quality too are the necessary determinants of the quality of life of its neighborhood. The UGS typically planned can be categorized as utilitarian and aesthetic or decorative or a combination of both. Another classification can be based on the use, namely, recreational, cultural and these providing ecosystem services. As stated earlier, the UGS rarely fulfil a singular purpose. The most common types of UGS are parks, playgrounds, greenbelts, green spaces around waterbodies, wetlands, landscaping around a plot/building, street avenues, roundabouts or rotary intersections and vacant and unused plots. These typologies in a planned city are categorized by their scale and size as well into plot level, neighborhood level, sector level and city level UGS.

\section{Benefits of Urban Green Spaces}

The advantages of the UGS have been realized owing to which these have been a part of the plans of the towns and cities since the earliest times. These can be traced back to the gardens developed by the emperors though largely for their personal use. Later as an outcome of the industrialization era resulted in the deterioration of the living conditions in the urban areas, the concept of garden city took root. Since, the incorporation of the green spaces has been an integral part of planning towns and cities. During the late 19th century, towns and cities began to be planned based on the garden city concept with more and more attention on health and sanitation.

Despite the enormous benefits that urban green spaces provide there is a serious lack of information about the quantity and quality of urban green spaces, specially in the context of India. The benefits of UGS can be categorized into ecological, social and economic. The ecological benefits include cleaner air, water and soil, and relatively lower temperatures. UGS improve the micro-climate and preserve the local wildlife. The social benefits are accrued from the UGS in form of enhanced social and cultural life which gets created due to greater opportunities for people to interact. Green spaces provide a safe place for children to play and contribute to their physical, mental and social development. Proximity of property to green spaces is known to have a higher value, especially in densely populated areas as well as in reducing the air conditioning load.

\footnotetext{
${ }^{5}$ an open space in or near a town, used as a parade ground or for events such as public meetings (Shabdkosh, 2020)
} 
Direct benefits of green spaces are reduction in energy consumption, ground water recharge, protection of lakes and streams from polluted runoff, reduced soil erosion, rainfall retention, water quality protection, reduced heat island effect and lesser overall temperatures.

An indirect benefit of urban green areas is a decrease in the crime rates of the area which has been substantiated by a study conducted in Philadelphia where it was found that areas where grass, trees and shrubs were found, crime rates, especially robberies and assaults were lesser [Wolf, 2004]. This has been corroborated by another study that the presence of large street trees was most important in reducing rates of crime [Donovan and Prestemon, 2010]. Green cover in an area is an indicator of the neighborhood being cared for and hence creating a perception in the mind of the criminal that (s)he may be watched.

Further, it is a well-established fact that the green spaces contribute to a high level of quality of life to its surrounding areas. As stated by (Lee, ordan and Horsley, 2015), Urban Green Spaces provide environmental benefits by negating urban heat and contribute to direct benefits by providing space to residents for physical activity and social interaction.

The inclusion of green spaces in urban areas of India is becoming more and more crucial so as to attain and maintain the quality of life standards. Over population and high density in the cities over time has led to scarcity of land and resources. One of the major impacts of increasing pressure on land has been decline in the open spaces. In parallel, it has been noted that with the inclusion of the green spaces in urban areas and making these accessible to the public has a direct correlation with the health of the residents.

\section{Case of Chandigarh}

Chandigarh was conceptualized as an urban organism with its major functions: living, working, care of the body and spirit and circulation, being equated with different parts of human body. In March 1948, the Government of the then erstwhile Punjab, in consultation with the Government of India, approved a 114.59 Sq. KMs (11,459 hectare) area at the foothills of Shivaliks as the site for the new capital. The City was designed for a population of 5,00,000 and density of approximately 4,400 persons per Sq. KM (44 persons per hectare) [Census of India, 2011]. Subsequently, with the reorganization of the erstwhile State of Punjab in 1966 into present day Punjab, Haryana and Himachal Pradesh, the city of Chandigarh assumed the unique distinction of being the capital of two states, Punjab and Haryana and has had the status of a Union Territory, governed by the central government through an appointed governor.

Albert Meyer, an American planner and architect, was hired in 1949 to formulate the plan of Chandigarh city. Mayer developed a superblock ${ }^{6}$ based city threaded with green spaces which emphasized the cellular neighborhood and traffic segregation. The

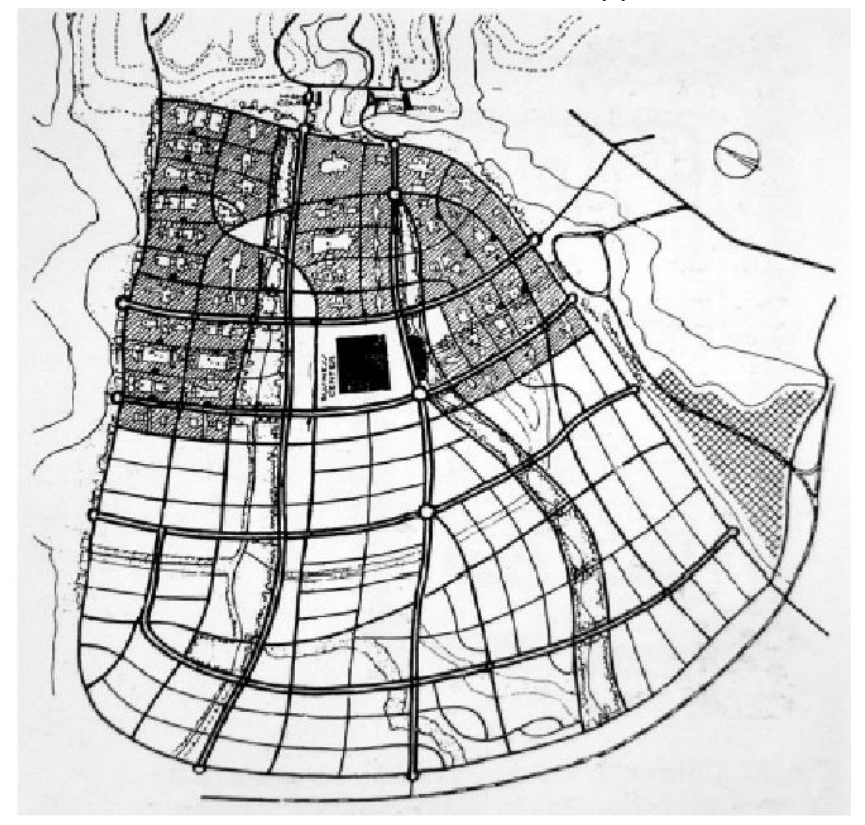

Figure 4.1Chandigarh City Plan by Albert Mayer Source: Mayer, Albert A. Papers, [Box 18, Folder 28-29], Special Collections Research Center, University of Chicago Library

\footnotetext{
${ }^{6}$ Superblock is an area of urban land bounded by arterial roads that is the size of multiple typically sized city blocks. (Super Blocks, 2020)
} 
City's site had certain inherent landscape features, which were fully retained as well as integrated into the plan like the gentle grade was used to promote the drainage and streams to orient the plan (Chandigarh Master Plan 2031) (Refer Figure 4.1).

The natural features of the site consisted of the panoramic range of the Shivalik Hills, the gently sloping landform from the North-East to the South-West, seasonal rivulets on its north-western and south-eastern flanks; and an eroded valley with a small nallah7 running through the centre (Chandigarh Master Plan 2031).

The conceptual design was further detailed by young architect, Mathew Nowicki in Mayer's team, who gave it a touch of artistry and monumentality as he synthesized it into a simple pattern 'The leaf', bringing in the element of sensitization towards the environment and ecology from the inception into the plan (Refer Figure 4.2).

Finally, Le Corbusier's approach was adopted which manifested in planning and architecture through the use of minimal ornamentation, repetitive unit and separation of land use and zoning. The city plan was conceived as post war Garden City ${ }^{8}$ wherein vertical and high-rise buildings were ruled out, keeping in view the socio economic-conditions

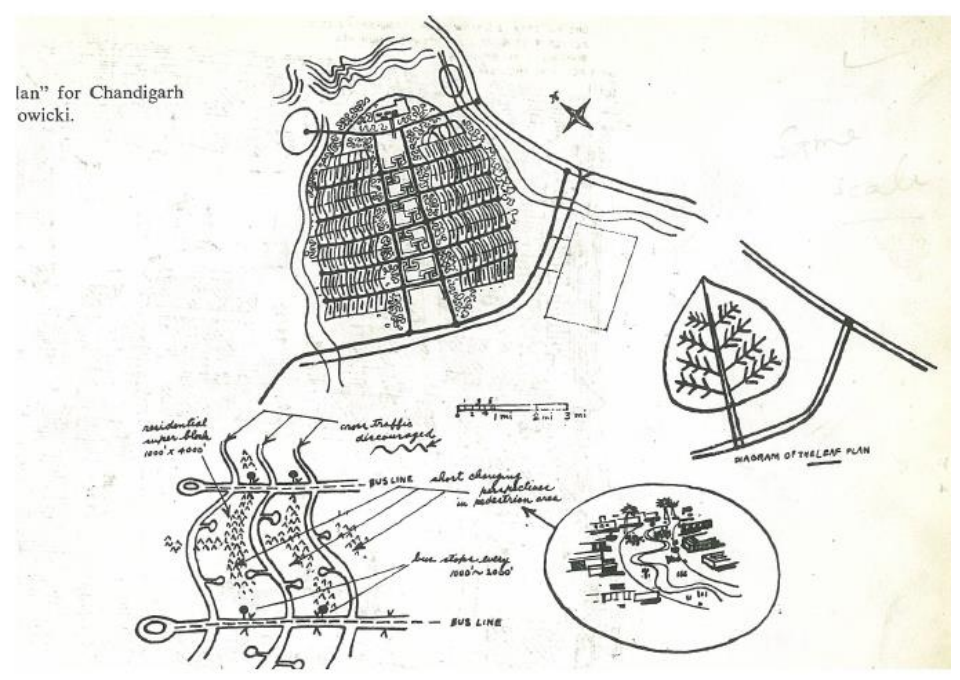

Figure 4.2 The 'Leaf Plan' of Chandigarh conceptualised by Mathew Novicki

Source: Mayer, Albert A. Papers, [Box 18, Folder 28-29], Special Collections Research Center, University of Chicago Library and living habits of the people.

The City has been planned at hierarchial levels, neighborhood being at micro level and City being the meso level. The neighborhood level is organized as sectors of rectangular shape of about one square kilometer each functioning as the basic unit. Le Corbusier planned the Capitol Complex at the top (North) of Chandigarh city resembling the head; the intellectual base, reflecting his conviction that governance should be in north as the head rules the body. Residential sector constituted the living part whereas the Capitol Complex, city center, Educational Zone (Post Graduate Institute, Punjab Engineering College and Punjab University) and the Industrial Area constitute the working part. The Leisure Valley, Gardens, Sector Greens and Open Courtyards were designed to represent the care of body and spirit. The circulation system comprised of 7 different types of roads known as 7 Vs. Subsequently, pathways for cyclists called V8 were added to the circulation system [8]. Combining modernity with ecology, eight kilometers long linear park was planned to run through the city from its north-eastern tip to its south-western end forming the city level urban green (Refer Fig 4.3).

\subsection{Green Spaces in Chandigarh}

Importance of green spaces for the well-being of humans has been well established through research, especially after the World War II. In concurrence with thought, Corbusier kept the provision of large

\footnotetext{
${ }^{7}$ Nallah is a runnel or a brook (Shabdkosh, 2020)

${ }^{8}$ method of urban planning proposed in 1898 by Sir Ebenezer Howard in the United Kingdom were in the urban areas were planned to be self-contained communities surrounded by greenbelts, containing proportionate areas of residences, industry and agriculture (Howard, 1902).
} 
number of open spaces, green belts, city parks and neighborhood parks in Chandigarh right from the beginning. There exists well-structured order in the hierarchy of open spaces in the city ranging from the neighborhood level to the city level. The major principle which guided the formulation of Chandigarh's landscape design was that its original topography has to be retained and integrated (Chandigarh Master Plan 2031). Provision of green spaces in each sector were basically meant to provide lungs to the area and for developing areas of leisure. Unlike other Indian cities the green areas in the Chandigarh city are planned within each sector, which is the neighborhood level.

Green Spaces have been planned at each sector level in the form of neighborhood parks and playgrounds. There are a series of community spaces and city level parks like Rose Garden and Rock Garden. The hierarchy of services as stated in the Guidelines has been followed in case of Chandigarh.

The City's green identity has been established through its long clear cut vistas created in the first phase of the city connecting the residents to the skyline of the hills through continuous green spaces such as sector greens, Leisure Valley and Sukhna Lake promenade. tree plantation and landscaping have been integral part of the city's Master plan.

Additionally, green open spaces are available either in the form of private housing, schools, colleges or other institutional large campuses such as Punjab Engineering College, Panjab University; over and above the planned green areas in the city layout, contribute as much as the overall city greenery and open spaces.

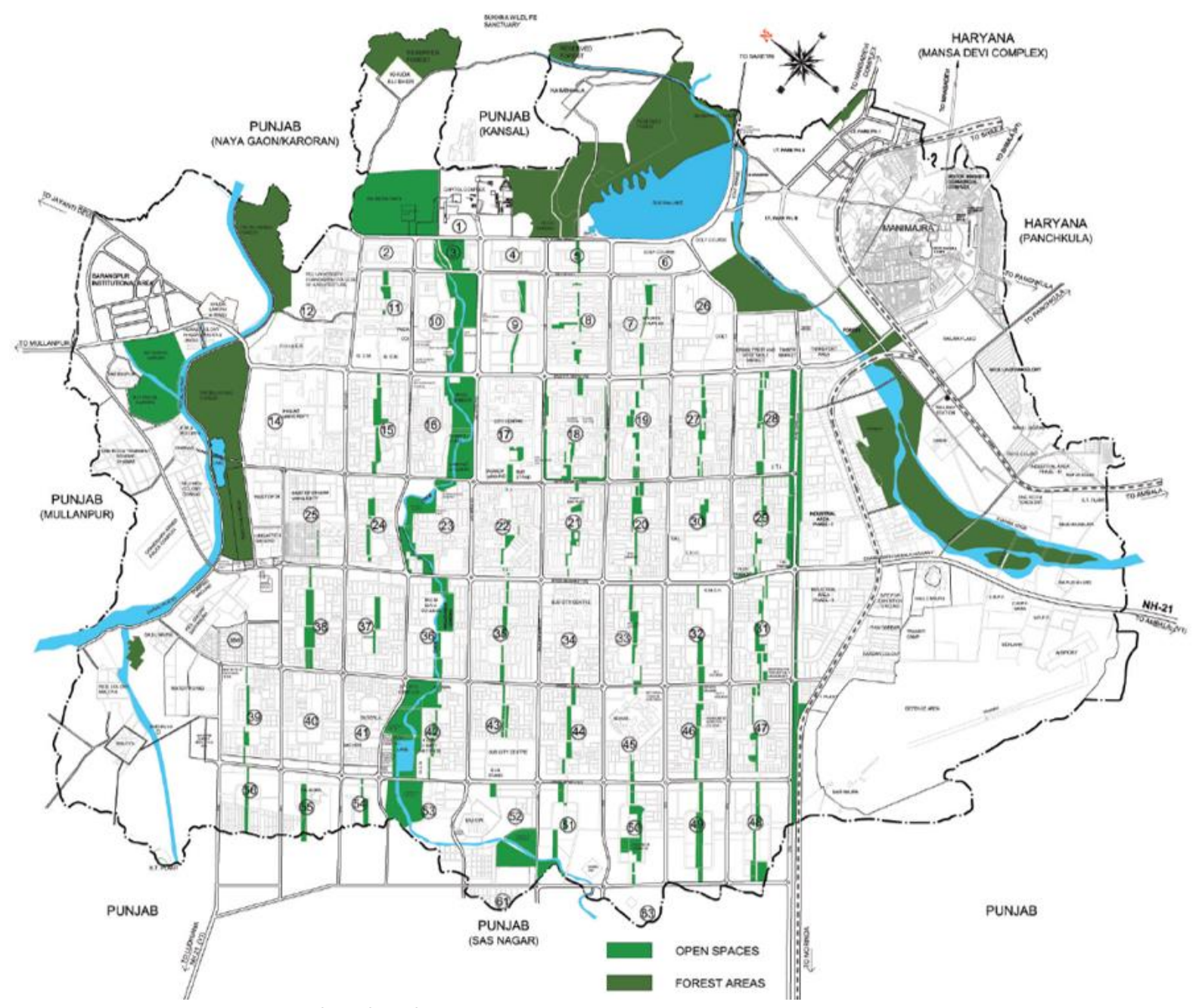

Figure 4.3 Green Spaces in Chandigarh City

Source: Chandigarh Master Plan 2031, Chandigarh Administration 
The trees along roads, open spaces, green belts around building complexes have been based on study of the movement of sun in relation to direction, scale, size and architecture along avenues. To minimize glare along the avenues running north-east to south-west, dense foliage evergreen trees and the shopping streets have been planted with flowering species (Abigal, 2014). (sentence formation?)

\subsection{UGS Policies in Chandigarh}

As stated in the Chandigarh Master Plan 2031, the seeds of extensive landscaping were embedded in the city's layout plan by its architect-planner Le Corbusier right at the beginning, with the provision of large number of open spaces, green belts, city park and neighborhood parks. The current Master Plan recoganised the need for conservation of the green heritage in future specially in light of the rapid development of the city in the last few decades.

The city does not have any incidental or random left-over open spaces but has well planned orderly hierarchy of green spaces. It is recoganised by the administration that not only are these spaces to be protected in the future due to rapid densification of the city but the green heritage of the city is to be nurtured.

Green spaces exist not only in a planned hierarchial structure from neighbourhod to city scale but are found as huge chunks of open spaces as part of the institutional areas as well. The Zoning Plans of group housing mandates 15 per cent of community open spaces within campuses to maintain closeness with nature and for outdoor activities (Chandigarh Master Plan 2031).

The Master Plan has adopted the Urban Development (UDPFI) norms for open spaces ranging between 10 square meter to 12 square meter per person comprising of parks, play fields, specified parks, amusement parks, maidans, multi-purpose open spaces, botanical garden, geological park and traffic park. The city has a thorough planned tree plantation system, along its varied hierarchy of roads and open spaces which has been preserved in the older sectors and extended to the new sectors.

\subsection{Temporal Changes in Greens Spaces}

Urban green space in Chandigarh's Master Plan is a component of 'green infrastructure', that comprises of all urban land covered by vegetation of any kind. This covers vegetation on private and public grounds, irrespective of size and function, and also include small water bodies such as ponds, lakes or streams known as the 'blue spaces' (WHO, 2017).

It must be noted that in the first phase of development, the city had 19.69 percent area under greens spaces. In 2001, average green spaces available was 17 square meters per person which is projected to be at 10.7 square meters per person by 2031 as per the Master Plan of 2031. The City's green cover rose from 21 per cent in 1991, 29.3 in 2003 to 35.7 in 2007 to 41 in 2017 and 46 percent in 2019 as per Forest Survey of India's Report 2007 and 2019. The per capita green space availability in the city presently is around 54.45 sq. meters which is better than most of the European cities (Chaudhry and Tiwari, 2011).

\section{Survey and Analysis}

Urban Green Spaces are critical for the health of people. The survey has been designed to assess the usability, accessibility and the benefits of the Urban Green Spaces. This survey focused on understanding the residents use Urban Green Spaces in their everyday life. Respondents were encouraged to discuss the perceived effects the green spaces have had on their health and the changes experienced, if any, pre- and post-lockdown caused due to the COVID19 pandemic.

An online survey designed in Google Form was sectioned in three parts. With the aim of understanding 
residents' preferences, personal values, and environmental priorities regarding the green spaces, a questionnaire survey was designed, formulated, and distributed to a random sample of the residents in the city, with an attempt to cover all the sectors of Chandigarh.

The initial part of the survey was prefaced by an explanation of the purpose of the study followed by first part consisting of questions about socio-demographics (age, gender and place of residence). The second part had questions focused on accessibility to the green paces and the use to which these were put to by the respondents. The questions comprised of the awareness about parks and green spaces, including proximity to the green space, the frequency of visit, purpose of visit, type of frequently visited parks and the benefit accrued thereof. It included the impact the pandemic induced lockdown had on the accessibility and use of the green spaces and its manifestation on the health of the residents.

The third part focused on residents' perceptions, issues and aspirations for their city's public green spaces. The survey measured the importance the respondents attributed to public green space characteristics. Whether the existence of natural features contributed to social cohesion in their neighborhood? Whether the existence of neighborhood green spaces contributes to a better quality of life?

The questions were on the problems in the green spaces, if any as well and the methods to improve these. Data on the overall satisfaction with the neighborhood and city level green spaces, and their desires regarding future investments in city's green spaces was also captured.

So as to access the usability and accessibility of the urban green spaces questions like primary purpose of using these spaces, proximity to such spaces in time and distance, frequency of visit to these spaces as asked. The residents were asked about the differences if any that may have been caused due to the COVID19 induced pandemic.

These questions were about the frequency of the visit before and after the lockdown - if the movement restrictions imposed by the government due to the COVID19 pandemic impacted their visits to the green spaces and if this restriction impacted their health. Questions were further asked to know the type of this impact on their health and the measures adopted by the respondents to overcome the health issues. Further, questions were asked if easing of the lockdown restrictions led them to restart using the urban greens spaces as in the pre-pandemic period. Questions were also asked on the coping mechanism that were used by residents to overcome the health issues faced during the pandemic.

The results showed that 57 per cent of the respondents were females. The age group distribution of the respondents showed that 90 percent were in the age group of 21 to 60 years with 29 percent being between 41 - 50 years and 42 percent being less than 40 year of age. Only one percent were above age 70. As regards the place of residence, the distribution was nearly equal with respect to $A, B, C$ and $D$ parts of the sector which may be considered indicative of the economic status of the residents.

As regards the accessibility to the green spaces, 75 percent of the residents stated that neighborhood parks were most accessible to them and were within a distance of 100 meters from their residence. This was at less than 5 minutes walking distance. This has been so because of the neighborhood concept plan of the sub sectors of the city, which is centered around the green space, that is the neighborhood park. 08 percent of the respondents stated that they were at a distance of 100 to 200 meters from the nearest green space, while 12.5 percent were at a distance of 200 to 500 meters with only 4.5 percent up a distance of one kilometer. No resident stated that they were at a distance greater than one kilometer from the nearest green space.

As regards the frequency of visits to the green spaces, 42 percent of the respondents stated that they visited the neighborhood parks at least once a day. While 25 percent stated once in two days visits, only 8 percent of the respondents were such who visited the parks twice in a day. Majority of these were either in the age group of 21 to 30 years or above 71 years. Amongst these, the younger age group were only 
females.

The response with respect to the use of the parks and green spaces showed that the residents primarily used the space for walks and or enjoying nature, 54.7 and 29 percent respectively. Only 13 percent respondents use the space for sports and cycling actively. While 2 percent used for yoga and 1.2 percent for socializing.

91 percent of the respondents stated that lockdown caused by pandemic had impacted their visits to the park. They further stated that their health got impacted due to the restrictions of lockdown. Though nearly 40 percent stated the impact being general weakness or increase in body weight due to lack of exercise, there were at least 15 percent respondents who stated that the impact had been on their mental wellbeing in form of increase in anger and aggression. Coping mechanism adopted by these respondents as stated had been in form of exercising and doing yoga at home. Some respondents stated that they started with activities like home gardening and other indulging in hobbies and meeting family and friends online.

09 percent who were negative in their response stated that they visited the neighborhood park either very early in the morning or very late in the evenings so as to avoid any kind of interaction with the people. Majority of the respondents resumed visiting the green spaces once the lockdown eased. However, there were 25 percent respondents who did not resume the activity, stating unsafe conditions as the reason.

As regards the visits to the city level parks, nearly 90 percent of the respondents did not visit the city level green space on regular basis. Only 08 percent of the respondents visited these spaces which had been possible for them due to the proximity of their residence to the city level parks, being less than 500 meters.

To identify how people value the roles of green spaces in neighborhood, the following questions were asked: How strongly do you agree or disagree with the following statements-Neighborhood green spaces can positively influence the health of residents; Neighborhood green spaces serve as habitats for local wildlife; Neighborhood green spaces contribute to the quality of life of residents; Neighborhood green spaces can contribute to the ecology of the broader environment; Neighborhood green spaces can contribute to the increase in property values; Green spaces within neighborhoods can contribute to a sense of belonging towards the community.

For residents' level of satisfaction with their green spaces, the following questions were asked: Are you satisfied with the amount of the green spaces in your community? Are you satisfied with the greenness of the green spaces in your community? Are you satisfied with the overall quality of the green spaces in your community? Are you satisfied with the maintenance of the green spaces in your community? The questions about residents' preferences included: if you or your neighborhood's representatives are involved in building natural green space in your neighborhood, what additions or alterations would you like to see the green spaces? Would you like to see small mammals in your community if they are not harmful to you and your property? In the past five years, have you ever been involved in nature activities such as birding clubs or a trees and shade program while you are living in the community? The questionnaire ended with an open question asking: Do you have any comments about the structure, arrangement, and nature of green spaces in your community and broader surrounding areas?

Nearly 92 percent of the respondents stated that green spaces positively influence their health and mental wellbeing. They strongly agreed that green spaces have an impact on the environment of the areas around. Nearly all residents who responded were satisfied with the quality of the spaces, though about 5 percent stated, specially in the $C$ and $D$ parts of the sectors stated some degree of dissatisfaction giving reasons as congestion, difficulty in access and poor maintenance. This was more so in the southern sectors of the city. The residents largely denied being involved in the development activities of the green spaces or in any nature or community activities in the green spaces in the city.

It is the percept of the authors that studies on correlation between human health and urban green space 
are especially relevant to governments, organizations, and communities that are making efforts to either introduce new or preserve existing green space for residents of urban areas. Urban planning and placebased initiatives are increasingly addressing not only economic and environmental priorities, but also public health goals. Cities are increasingly adopting an urban health agenda, which prioritizes the relationship between urban land, natural resources, and human health. These groups need evidence that is relevant to not only land and natural resource management but also health outcomes in urban areas.

\section{Conclusions}

Green spaces in residential communities are important yet understudied features of the urban ecological system. Given the fact that master-planned communities have become a prominent type of modern community development in urban India and considering the gradual and inevitable increase in urban population and density there are opportunities to offset the challenges resulting from such development and the lack of green spaces in urban areas in terms of quantity and quality.

The study analysed the access, usability of the green spaces in Chandigarh to establish the importance of the urban green spaces on human health. There is evidence that the access to green spaces is an important factor influencing mental health and well-being. It was well established through the results of the social survey that health of the respondents were impacted by the lockdown imposed by the government in order to contain the spread of pandemic. Further, it came out clearly that the residents valued the easy access to the neighbourhood greens and were largely satisfied with the available spaces. It can be concluded that the green spaces should be included in city's master plan and such spaces should be made easily accessible to all urban residents.

\section{References}

UN (2018), World Urbanisation Prospects-The 2018 Revision, United Nations

Chiesura, A., (2004). The role of urban parks for the sustainable city. Landsc. Urban Plan. 68, 129-138

Wolch, J.R., Byrne, J., Newell, J.P., (2014). Urban green space, public health, and environmental justice: the challenge of making cities 'just green enough'. Landsc. Urban Plan. 125, 234-244.

Wang, Dong; Brown, Gregory and Mateo-Babiano, I., (2013), Beyond Proxility: An Integrated Model of Accessibility for Public Spaces, Asian ournal of Social Sciences and Humanities.

Anderson, S. T. \& West, S. E. (2006). Open space, residential property values, and spatial context. Regional Science and Urban Economics, 36, 773-789

Colwell, P. F., Gujral, S.S., Coley, C. (1985). The impact of a shopping centre on the value of surrounding properties. Real Estate Issues, 10, 35-9.

Coughlin, R., Hammer, T. \& Horn, E. (1974). The Effect of a Large Urban Park on Real Estate Value. Journal of the American Planning Association, 40, 274-277.

Hannon, B. (1994). Sense of place: geographic discounting by people, animals and plants. Ecological Economics, 10, 157-174.

Veal, A. J. (2013). Open space planning standards in Australia: In search of origins. Australian Planner, 50(3), pp. 224-232.

WHO, (2016) Urban green spaces and health. Copenhagen: WHO Regional Office for Europe, 2016. 
Morar, T., Radoslav, R., Spiridon, L. C., \& Păcurar, L. (2014). Assessing pedestrian accessibility to green space using GIS. Transylvanian Review of Administrative Sciences, 10(42), pp. 116-139.

EPA, (2017), Open Spaces/Green Spaces, accessed at What is Open Space/Green Space? I Urban Environmental Program in New England I US EPA on 29 November, 2020

Maryanti, M. R.; Khadijjah, H.; Uzair, A. M. and Megat Mohd Ghazali, M. A. R., (2016), The urban Green Space Provision using the standards approach: issues and challenges of its implementation in Malaysia, Sustainable Development and Planning VII 369, WIR Transactions on Ecology and The Environment, Vol 210.

European Commission (2019), Future of Cities accessed at https://urban.jrc.ec.europa.eu/thefutureofcities on 03 December, 2020

United Nations, (2017), On the Implementation of Sustainable Development Goals, UN, New York.

Kulshrestha, S.K. (2006), Dictionary of Urban and Regional Planning, Kalpaz Publications

Government of India, (1996), Urban and Regional Development Plan Formulation and Implementation Guidelines, Ministry of Urban Development, Government of India, New Delhi.

Town and Country Planning Organisation, (2014), Urban Greening Guidelines, 2014, Ministry of Urban Development, Government of India.

Government of India, (2014), Urban and Regional Development Plan Formulation and Implementation Guidelines, Ministry of Urban Development, Government of India, New Delhi.

Bureau of Indian Standards, (2005), National Building Code of India, 2005 Group 1, Second Revision.

Shabdkosh, (2020) Meaning of Maidan, https://shabdkosh.raftaar.in accessed on 18 July 2020

Wolf, K.L (2004) University of Washington; http://www.cfr.washington.edu accessed on 03 December 2020

G. H. Donovan, J. P. Prestemon (2010) The Effect of Trees on Crime in Portland, Oregon. Environment and Behavior

Lee, Andrew; Jordan, Hannah and Horsley, Jason. (2015). Value of urban green spaces in promoting healthy living and wellbeing: Prospects for planning. Risk Management and Healthcare Policy. 8. 131. 10.2147/RMHP.S61654.

Census of India, (2011), District Census Handbook: Village and Town Directory, Government of India.

Mayer, Albert A. Papers, [Box 18, Folder 28-29], Special Collections Research Center, University of Chicago Library

Super Blocks (2020) https://www.thedesignresponse.com accessed on 21 August 2020

Chandigarh Master Plan 2031 (2016) Chandigarh Administration, Chandigarh

Shabdkosh, (2020) Meaning of Nallah, https://shabdkosh.raftaar.in accessed on 13 June 2020

Howard, E. (1902). Garden Cities: A Solution of the Housing Problem. Journal of The Sanitary Institute, 23(4), 670-674.

Weber, Abigal, (2014) unpublished thesis, Within the Edge: A revised approach to urban containment within Chandigarh Periphery, University of Washington. 
WHO (2017) Urban Green Spaces: A brief for action, World Health Organisation, Denmark

Forest Survey of India, (2007), State of Forest, Government of India

Forest Survey of India, (2019), State of Forest, Government of India

Chaudhry, Pradeep and Tewari, V. P. (2011) Urban Forestry in India: Development and Research Scenario, Interdisciplinary Environmental Review, Vol. 12, No. 1 